\title{
Roma Dönemi Efes ve Pompeii Duvar Resimlerinin İkonografik Açıdan Değerlendirilmesi
}

\author{
Şehnaz ERASLAN *
}

\section{Özet}

Efes duvar resimlerinin tarihi Hellenistik dönemden Bizans dönemine kadar uzanmaktadır. Bu makalenin içeriğini oluşturan Roma dönemi duvar resimleri 'Teras Ev 2'de bulunmaktadır. İmparatorluğun doğusunda yer alan kentlerden sadece Efes'te bu kalitede ve sayıda duvar resimleriyle karşılaşılmıştır. Efes duvar resimlerinde Hellen mitolojisinden sahnelerin yanı sıra filozoflar, peyzaj resimleri ve günlük hayattan kesitler de yer almıştır. Bu resimler, Roma resim sanatının Anadolu'daki en dikkat çekici örnekleridir.

Bu makalede, Efes'teki Roma dönemine ait duvar resimleri ile Pompeii duvar resimlerinin ikonografik açıdan karşılaştırmalı bir değerlendirilmesi yapılmaktadır.

Anahtar Sözcükler: Roma Dönemi, Teras Ev 2, Efes, Pompeii, Duvar Resimleri.

\section{Iconographical Evaluation of Ephesos and Pompeii Wall Paintings of Roman Period}

\section{Abstract}

Ephesian wall paintings has a history from the Hellenistic to the Byzantine Period. Related to our theme examples of Roman wall paintings are in the so-called 'Terrace House 2' of Ephesus. In the east of the Roman Empire only Ephesus has yielded such a wealth of wall paintings, in both number and quality. Roman wall paintings of Ephesus scenes are generally from Greek mythology, philosophers, landscape pictures and daily-life studies. These paintings are the most significant examples of Roman painting in Anatolia.

In this paper, the Ephesus wall paintings of the Roman period and the Pompeii wall paintings are evaluated comparatively from the aspect of iconographic styles. 


\section{Giriş}

Roma resim sanatı, Klasik ve Hellenistik dönemlerde sanat anlayışının bir sentezi olarak belirginleşmiştir. Bu durum dikkate alındığında, Klasik ve Hellenistik dönemlere ait orijinal eserlerin kopya edilerek Roma resim sanatında tekrar yer aldığını söylemek mümkündür. Dolayısıyla Roma resim sanatında yer alan konular Hellenistik kültürün etkisi altındadır. Bu nedenle Klasik ve Hellenistik dönemlerde çeşitli sanat eserlerine esin kaynağı oluşturan mitolojik konular, Roma sanatında da öncelikli olarak tercih edilmiştir.

Roma İmparatorluk döneminde Anadolu'daki Roma resim sanatının en dikkate değer örnekleri Efes antik kentinde bulunmaktadır. Efes duvar resimleri, Özellikle İtalya'da Roma resim sanatının yüksek kalitedeki örneklerinin bulunduğu Pompeii duvar resimleriyle birtakım benzerlikler içermektedir. Her iki yerin duvarlarında betimlenen mitolojik sahneler, filozof betimlemeleri ve teatral sahnelerin benzerliği oldukça dikkat çekicidir.

Bu çalışmada, Efes Antik Kenti'nde yürütülen kazı çalışmalarında ortaya çıkarılan duvar resimlerinin irdelenmesiyle bölgenin sanatsal kimliğine ışık tutacak önemli verilere ulaşılmış ve bu verilerin yardımıyla Roma resim sanatının Efes sanatındaki yeri ve etkileri değerlendirilmiştir. Ayrıca, Efes ve Pompeii duvar resimlerinin birbirleri ile olan benzerlikleri ya da farklılıkları üzerine ikonografik bir çalışma yapılmıştır.

\section{Roma Dönemi Efes Duvar Resimleri}

Roma Imparatorluğu döneminde Asya eyaletinin başkenti olan Efes'te eşsiz kalitede duvar resimleri bulunmuştur. Bu resimler, genellikle zengin Efeslilerin villalarının duvarlarını süslemişlerdir. Duvar resimlerinde işlenen konularda çoğunlukla mitolojik ve günlük hayattan kesitlerin tercih edildiğini görülmektedir. Efes duvar resimleri, Roma resim sanatının Anadolu'daki en dikkat çekici örnekleridir. Bu resimlerde, Anadolu'nun M. S. 1 - 6. yüzyıllarını aydınlatabilecek belge niteliği taşıyan, sosyal yaşam ve mimarisinin betimlenmiş olması, Efes duvar resimlerini ayrıcalıklı kılmaktadır.

Efes'te TerasEv 2'de, 75'tenfazla mekan duvar resimleriyle süslüdür; bunlara, yıkıntılar içinde ele geçmiş ve tavanlarla üst kat mekanlarına ait çok sayıda fragman eklenmektedir. Bugüne kadar elde edilen Efes duvar resimlerinde ağırlıklı olarak mitolojik konular, tanrılar, musalar, filozoflar, peyzaj resimleri ve ayrıca hizmet eden veya avlanan Eros örnekleri bulunmaktadır (Ladstater, 2012: 135).

\section{Roma Dönemi Pompeii Duvar Resimleri}

Pompeii, İtalya'nın Campania Bölgesi'nde, Napoli yakınında, Akdeniz'e yakın bir konumdadır. Roma döneminde üç yüzyıldan daha kısa bir süre varlığını sürdüren kent, M. S. 79 yılında Vezüv yanardağının patlaması sonucu volkanik küllerin altında kalarak tarih sahnesinden yeniden keşfedilene kadar silinmiştir. 1748'den itibaren yapılan çeşitli kazılarda ortaya çıkarılan evler ve içlerinde bulunan malzemelerin korunmuş olması Arkeoloji bilimi için yenilikler de sağlamıştır. Özellikle evlerin duvar resimleri ve mozaikleri Hellen ve Roma kültürlerine ait pek çok verinin elde edilmesi açısından da önemlidir. Pompeii evlerinin duvarlarını süsleyen resimler hakkında ilk çalışmayı Alman Arkeolog August Mau 'Geschichte der Decorativen Wandmalerei in Pompeii' adlı eserinde yapmıştır. Mau, bu eserinde duvar resimlerini dört stile ayırmıştır: I. stilde sıva üstüne çeşitli renklerle yapılan dikdörtgen panellerde mermer levha imitasyonları; II. stilde ışık ve gölge tekniği kullanılarak gerçeğe yakın yapılmış mimari yapılar; III. stilde yatay ve dikey olarak üç bölüme ayrılan duvarın orta kısmına yerleştirilen figüratif temalar; IV. stilde ise II. stil gibi perspektif olarak etkileyiciliği bulunan mimari elemanların yapımının tercih edildiğini bildirmektedir (Zimmermann ve Ladstätter, 2011: 10,11).

M. Ö. 2. yüzyıl ile M. S. 1. yüzyıl arasına tarihlendirilen Pompeii resimlerinde mitolojik konular, manzara, günlük yaşam, natürmort, tarihi konular ve portre gibi konular resmedilmiştir (Ragghianti, 1968: 110). 


\section{Mitolojik Sahne}

Efes'te Hellen mitolojisinin konularından esinlenerek resmedilmiş birçok duvar resmi bulunmaktadır. Bu mitolojik konular arasında yer alan 'Akhilleus'un Skyros'ta bulunması' sahnesi 4 no'lu evin peristilinin Güney koridorunda in situ olarak görülebilmektedir (Zimmermann ve Ladstatter, 2011: 84, fig.127,3).

Hellen mitolojisinde Peleus ve deniz tanrıçası Thetis'in oğlu olarak bilinen Akhilleus, Troia Savaşı'nda Hellenlerin en büyük savaşçısı olarak yer almıştır (Homer. Il. i. 538, xviii. 35; Hesiod. Theog. 244). 'Akhilleus Skyros'ta sahnesi', Akhilleus'un Troia savaşında yer alan mitolojik temalarından biridir. Antik dönem mitograflarına göre, Akhilleus'un Troia savaşına katılırsa öleceği kehanetini bilen Thetis, oğlunu Skyros adasına, Kral Lykomedes'in sarayına gönderir. Akhilleus Lykomedes'in sarayında, tanınmamak için kadın kılığına girerek kralın kızları arasına karışır. Fakat Akhaların kahini Kalkhas'ın, Akhilleus sefere katılmazsa Troia'nın alınamayacağını bildirmesi üzerine, Odysseus, onu aramaya başlar. Skyros adasında Kral Lykomedes'in sarayında olduğunu öğrenen Odyyseus, Akhilleus'u kadınların arasından ayırt etmek için bir plan düşünür. Diomedes ile birlikte satıcı kılığında saraya gider ve getirdiklerini kadınların beğenisine sunarlar. Kumaş ve mücevherlerin arasında, silahlar ve müzik aletleri de bulunmaktadır. Bohçasından çıkardığı silahları birbirine vurarak ve aynı zamanda düşman istilasını haber veren trompet eşliğinde çıkardıkları seslerle genç kahramanın savaşçı içgüdülerini uyandırmayı başarırlar. Böylelikle kimliğini açığa veren Akhilleus, Odysseus tarafından bulunarak Troia savaşına götürülür (Homer, II. Ix.668; Apollod. Bibl. c.; Hygin. Fab. 96; Stat. Achil. ii. 200; Ovid, Met.13.162-170). Odysseus onu götürse de Akhilleus kendi kaderini kendi seçmiş bir kahramandır. Illyada'da, annesi Thetis'in de daha önceden kendisine söylediḡi, önünde duran iki seçeneği Akhilleus şu şekilde dile getirir: "iki ayrı kader götürecek beni ölüme: Burada kalır, savaşırsam
Troia çevresinde, tükenmez bir ün var, dönüş yok. Dönersem yurduma, sevgili baba toprağına, ünüm olmasa da çok yaşayacağım, ölüm öyle çabucak gelip çatmayacak." (Homer. II. IX, 411 vd.).

Efsaneye uygun olarak resmedilen panoda, Akhilleus kadın kıyafetleri içerisinde görülmektedir (Resim 1). Solunda ise Akhilleus'u açığa çıkaracak olan asker trompeti üflemektedir. Resimde, zemin yeşil, figürler ise kahverenginin tonlarıyla oluşturulmuştur. Figürlerin tasvirinde kullanılan koyu ton ile zemin arasında ton kontrastı oluşturulmuş ve görsel bütünlük sağlanmıştır. Resimde ışığın etkisi parlaktır ve gölgeli alanlarda kendini göstermektedir. Figürler sert ve koyu renkte kontur çizgileriyle belirginleştirilmiştir. Koyu konturlardan formların iç bölgelerine doğru koyuluk dereceleri yavaş yavaş açılmış ve açık renk bölümler ışık almış gibi görünmüştür. Bu da figürlerin üç boyutlu formunu ortaya çıkarmıştır.

Akhilleus'un Skyros'ta bulunmasını konu alan resimlerden biri de Pompeii'de tasvir edilmiştir (Maiuri, 1953: 73-74; Delbarre-Fuchs-Paratte, 2007: 41). Dioscurlar Evi'nin duvarlarından birini süsleyen resim, Napoli National Müzesi'nde sergilenmektedir (Resim 2). Gelişmiş bir stile ve kompozisyon uyumuna sahip olan bu resimden geriye kalanlar, Hellenistik dönemdeki orijinalinin ne derece etkileyici olabileceğini göstermektedir. Tabloda, kadın kıyafetleri giyinmiş Akhilleus, Skyros'ta kral Lykomedes'in sarayında, Odysseus ve Diomedes'nin kendisini bulması sonucu şaşkına döndüğü an resmedilmiştir. Odysseus ve Diomedes, ellerindeki silahları birbirine vurarak çıkardıkları seslerle genç kahramanın savaşçı içgüdülerini uyandırmaya çalışmaktadırlar. Akhilleus ise bu durumdan rahatsız olmuş ve kaçmaya çalışmaktadır. Akhilleus'un sevgilisi Deidamia şaşkınlık içinde resmedilirken, kral Lykomedes ise kendinden emin ve hareketsiz olarak tasvir edilmiştir. Soğuk tonlarda sıradan bir çerçeve içinde bulunan tabloda yoğun renk kullanımı hakimdir. Akhilleus'un üzerindeki kadın kıyafetleri ise tablodaki diğer renklendirmelerin 
aksine gri tonlarında resmedilmiştir. Renk renk elbise furyası içinde gri renklerdeki elbisesiyle fark edilen Akhilleus'un ergen çağındaki çocuksu vücudu, etrafındaki Odysseus ve Diomedes'in erkeksi vücutlarıyla tezat oluşturmaktadır. Akhilleus'un gözlerindeki parıltıyı ve bakırımsı renklerdeki saçlarını gerçeğe yakın tasvir edebilen Pompeii sanatçısının sanatsal duyarlılığı dikkate deḡerdir. Ressam ayrıca Odysseus'un koyu renk teni ve kaçmakta olan Deidamia'nın ten rengi arasında kontrast oluşturmuş ve böylelikle uyum ve kontrastı meşhur bir resimde bir araya getirmiştir.

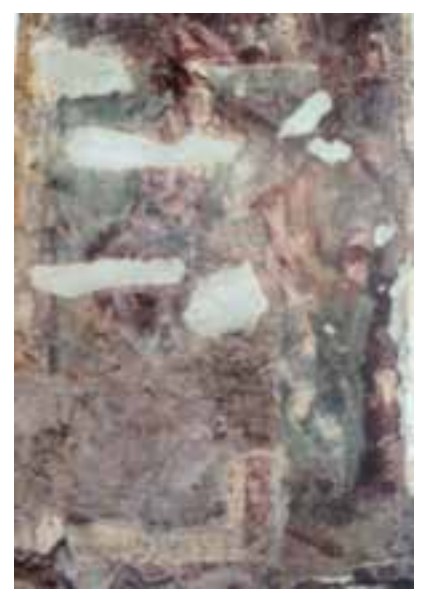

Resim 1. Akhilleus'un Skyros'ta bulunma sahnesi (ZimmermannLadstatter, 2011: 84, fig.123,3).

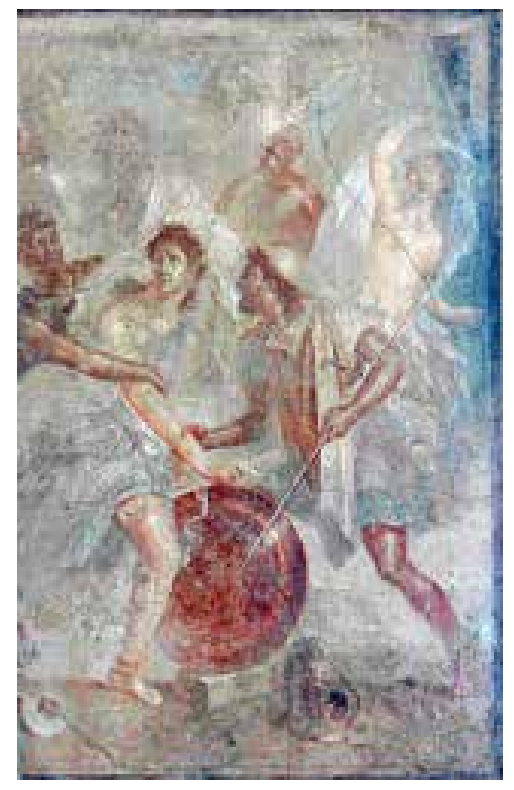

Resim 2. Pompeii, Akhilleus'un Skyros'ta bulunma sahnesi (Maiuri, 1953: 73).
Pompeii örneḡinde de, Efes örneğindeki gibi, resmin zemini açık yeşil ve açık kahverengi tonlarına ışık efektlerinin ilave edilmesiyle oluşturulmuştur. Akhilleus'un her iki yanındaki figürler daha koyu renklerle yapılarak Akhilleus ön plana çıkarılmaya çalışılmıştır. Ayrıca, insan figürlerinin dikey ve hareket halindeki duruşlarına karşın, önde ve arkada zırhların yatay hareketleri ile yön kontrastlığı oluşturulmuştur. Bu durum, kompozisyondaki önemli bir ritim unsurunu oluşturmaktadır.

Antik dönem yazarlarından Pliny (1950: 132), Akhilleus'un Skyros'ta bulunma sahnesini M. Ö. 4. yüzyılın sonlarında meşhur olan ressam Maronea'lı Athenion'un tablolarında betimlediğini belirtmektedir. M. Ö. 4. yüzyılın sonlarına doğru Maronea'lı Athenion gibi ressamlar renk ve ışık uyumunun birlikteliğini resimlerine başarıyla uygulamaya başlamışlardır (Charbonneaux vd., 1973: 125). Hellen ve Roma resimlerinde Akhilleus'un Skyros'ta bulunma sahneleri, Maronea'lı Athenion'un eseriyle bağlantılı olmalıdır. Dolayısıyla bu duvar resminin de muhtemelen Maronea'lı Athenion'un eserlerinden birinin kopyası olduğunu düşünmekteyiz. Pompeii'de bu sahnenin benzer örnekleriyle karşılaşmaktayız (Resim 3).

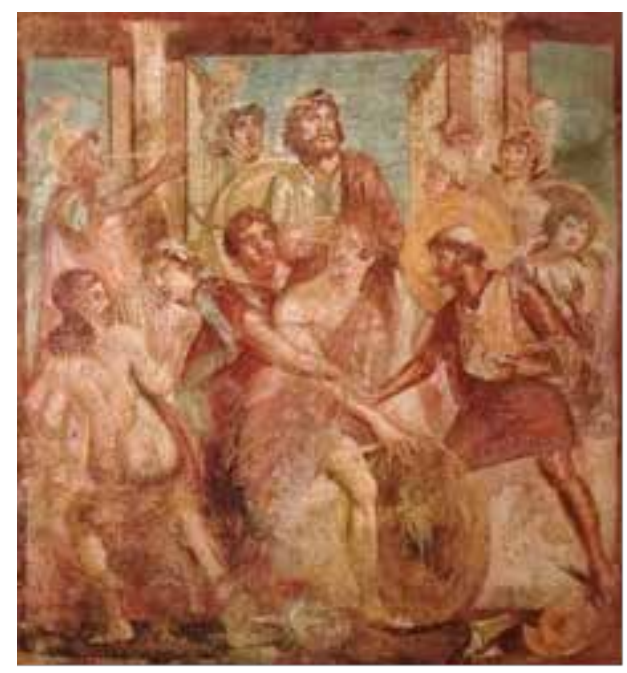

Resim 3. Pompeii, Akhilleus'un Skyros'ta bulunma sahnesi (Charbonneaux vd., 1973: 126, fig.124).

Arkaik, Klasik ve Hellenistik dönemlerde çeşitli sanat eserlerine esin kaynağı oluşturan mitolojik konular, Roma sanatında da önem kazanmıştır. Bu mitolojik temalar, duvar resimlerinde olduğu kadar, evlerin tabanlarını 
süsleyen mozaiklerde de karşımıza çıkmaktadır. Özellikle M.S. 1. yüzyıldan itibaren mitolojik temaların tasvirlerini Roma Dönemi'nin mozaik panolarında sıkça görmekteyiz (Dunbabin, 1999: 162; Hachlili, 2009: 14).

Roma dönemine ait Akhilleus'un Skyros'ta bulunması sahnesinin tasvir edildiği yaklaşık 15 mozaik bulunmuştur. Bu mozaikler Türkiye (Zeugma), ìspanya (Pedrosa), Kuzey Afrika (El Jem), Moritanya (Cherchel,Tipasa), Galya (Saint-Romainen Gal) ve Germanyáya (Orbe) kadar imparatorluğun tüm bölgelerinde karşımıza çıkmaktadır (Ling, 1998: 73; DelbarreFuchs-Paratte, 2007: 35).

Akhilleus'un Skyros'ta bulunması sahnesi Anadolu'nun batısında olduğu kadar doğusunda da sevilen bir tema olmuştur. Zeugma'daki mitolojik sahnelerin yer aldığı mozaik panolarından birinde de Akhilleus'un Skyros'ta bulunmasını konu alan sahne betimlenmiştir. Poseidon Evi'ndeki sığ havuzun zeminini süsleyen mozaik, M. S. 3. yüzyılın ortalarına tarihlendirilmektedir (Önal, 2002: 22; Abadie-Reynal, 2002: 746) (Resim 4). Sahnenin ikonografik açıdan Efes ve Pompeii örnekleriyle benzerlik gösterdiği söylenebilir. Bu benzerlik daha çok kumaşlardaki ışı-gölge kontrastı, Akhilleus'un kadınsı vücut hatları, figürlerdeki hareketlilik ve üç boyut yaratma çabasında göze çarpmaktadır.

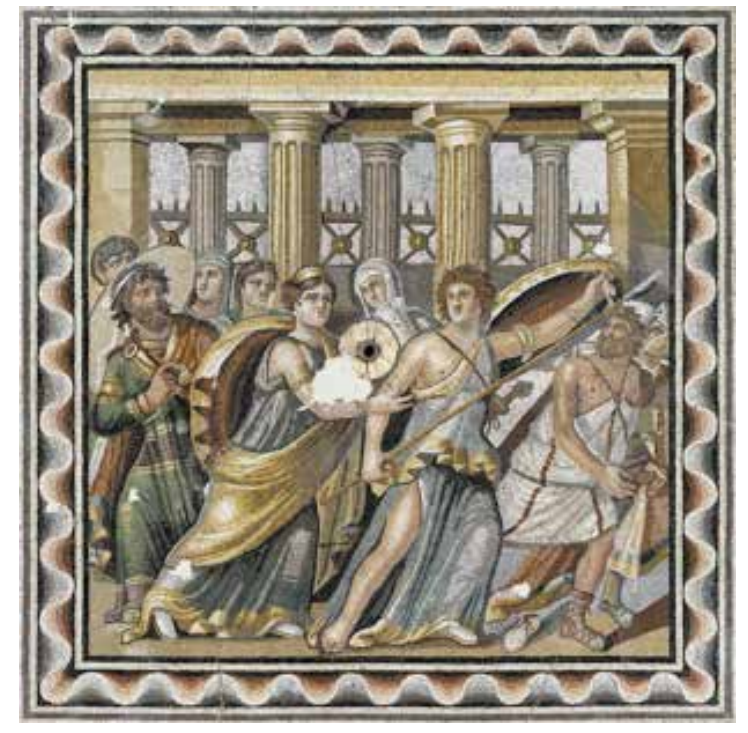

Resim 4. Zeugma, Akhilleus'un Skyros'ta bulunma sahnesi (Önal, 2002: 22).

\section{Filozof Sahnesi}

Efes'te filozof tasvirleri de sevilen bir tema olarak resimlerde yer almıştır. Bunlar arasında en göze çarpan Sokrates, 4 no'lu konut biriminde bulunmuştur. Filozof Sokrates mermer bir koltuğun üzerinde oturur durumda resmedilmiştir (Resim 5).

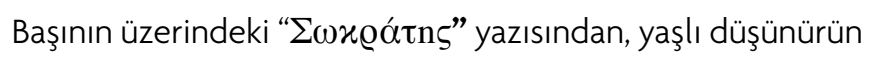
Sokrates olduğunu anlamaktayız. Filozof ileriye doğru düşünceli ve dalgın ifadeli bakışlarla betimlenmiştir. Ünlü düşünür oturduğu koltukta sağa doğru dönerek sağ elini koltuğa dayamış, sol eliyle ise asasını tutmuştur. Ressam, Sokrates'i daha belirgin kılmak için mantosunu beyaz boyayla işleyerek zeminle kontrast oluşturmuş ve Sokrates'i kompozisyonun optik merkezi haline getirmiştir.

Pompeii'de Boscoreale villasında bulunan bir duvar resminde de yaşlı bir düşünür resmedilmiştir (Maiuri, 1953: 65) (Resim 6). Yaşlı düşünür kaygılı ve sert mizaçlı olarak betimlenmiştir.

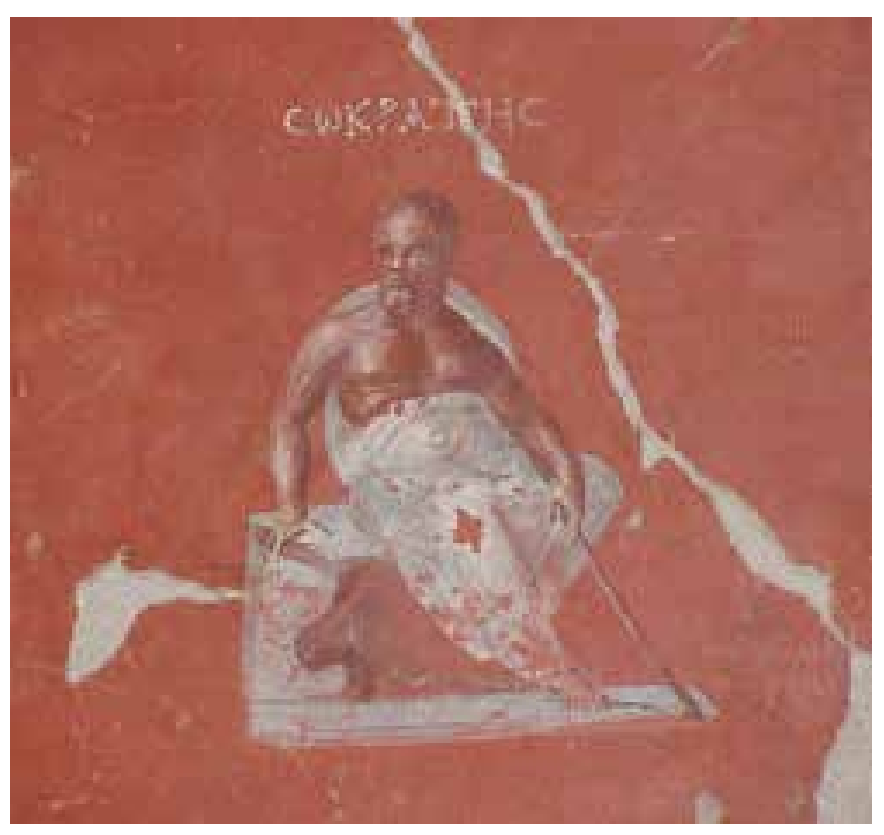

Resim 5. Efes, Sokrates (Zimmermann-Ladstatter, 2011: 84, fig.127,1).

Pompeii'de bulunmuş filozof tasviri, tıpkı Efes örneğindeki gibi kırmızı zemin üzerine resmedilmiştir. Her iki resimde de filozoflar yaşlı ve durağan tasvir edilmiştir. Efes örneğindeki filozof oturmuş, Pompeii örneğindeki 
ise elindeki sopaya dayanarak ayakta betimlenmiştir. Her iki örnekte de Hellenistik geleneğe bağlı kalarak oluşturulan mitolojik sahne ve figürlerin idealize edilmesi, renk geçişleriyle sağlanan üç boyut etkisi açıkça gözlemlenmektedir.

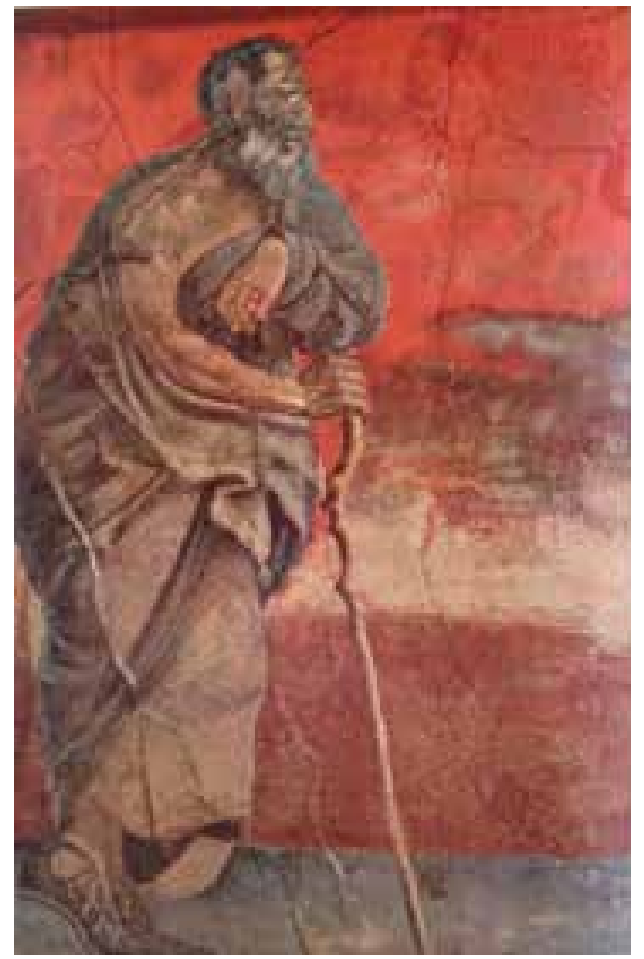

Resim 6. Pompeii, Filozof (Maiuri, 1953: 64).

\section{Eros Sahnesi}

M. S. 230 civarında IV. yapı evresinde çok kapsamlı yeni bir donanım uygulaması daha ortaya çıkmıştır. Bu donanım, duvar dekorunun modernizasyonuna da imkan tanımıştır. Zamanın zevkine uygun olarak duvarların üzeri mermer kaplanmış izlenimi veren boyalarla resmedilmiştir. Ayrıca, çiçekli duvar resimlerinin yanı sıra, Eros ve girland betimlemeleri de tasvir edilmiştir. Özellikle 2 no'lu konut birimi bu şekilde tasarlanmış bir dekorasyona sahiptir. Bu evin peristilli avlusunun duvarlarını mermer taklidi yapılmış levhalar üst kuşağında ise mavi fon üzerinde bir Eros'lu ve girlandlı friz tasvir edilmiştir (Resim 7). Uçan Eros'lar meyve girlandları taşırlar. Oscillum'lara asılı, sarı renkli ince girlantlar ise, bu meyve girlandlarını yarım girland kaydırılmış şekilde kesmektedir (Ladstater, 2012: 135-149).

Hellen mitolojisinin en önemli kaynaklarından olan Hesiodos'un Theogonia'sında Eros, evrenin yaradılış bölümünde yerini almaktadır. Hesiodos'e göre başlangıçta sonsuz boşluk Khaos vardı. Bu boşluktan Gaia (Toprak Ana) doğdu ilkin; sonra ölüler ülkesinin en derin yeri Tartaros; sonra Eros (Aşk) doğdu; sonra yer altı karanlığı Erebos’la yeryüzü karanlığı Nyks (Gece) doğdu (Cömert, 1999: 3). Hesiodos'un da belirttiği gibi Eros, antikçağın en eski metinlerinden beri evrende birleşme ve üretmeyi sağlayan doğal bir güç olarak karşımıza çıkmaktadır (Erhat, 2004: 106).

Klasik dönemde Eros'lar on iki, on üç yaşlarında çocuk, Roma İmparatorluk döneminde ise bebek olarak betimlenmiştir (Robertson, 1992: 247). Resim ve mozaik sanatında Eros'ları yunuslarla birlikte betimlemek Hellenistik dönemde karşımıza çıkmaya başlar. Roma İmparatorluk dönemi ile birlikte Eros'ları, özellikle resim ve mozaiklerde bebek biçiminde, kimi zaman yunusa binmiş balık avlarken, kimi zaman da girland taşırken ayakta görebilmekteyiz (Eraslan, 2011: 19).

Eros'ların girland taşıyarak tanrı ya da tanrıçaların etrafını süsleme sahneleri M. Ö. 5. yüzyıldan itibaren antik sanatta işlenmiştir. M. Ö. 5. yüzyıla tarihli ressam Meidias'ın boyadığı hydria'da Eros'lar, Phaon ve Demonassa'nın etrafını ellerinde tuttukları girlandlarla çevrelemektedir (Arias, 1962: fig.216). Eros'lar bu dönemde genellikle kutsayan figür geleneğini anımsatmaktadır.

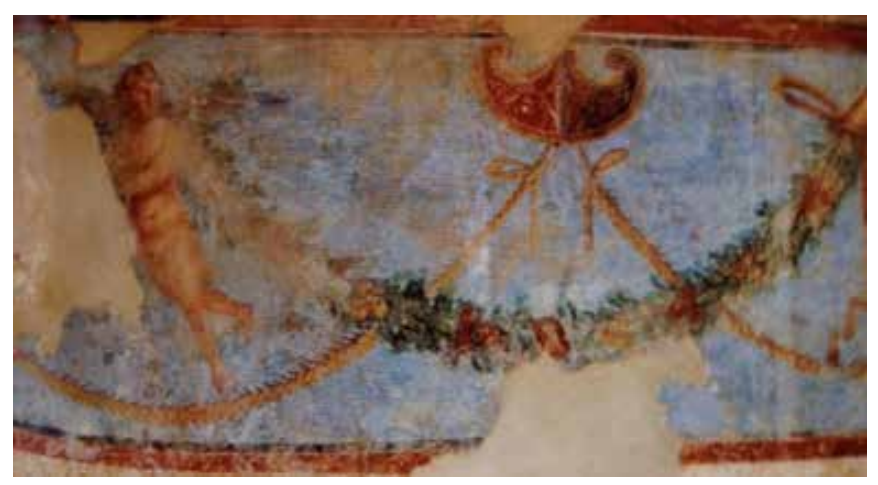

Resim 7. Efes, Eros ve girlandlar (Ladstatter: 2012: 143, Res.126). 
Girland ve Eros birlikteliği Pompeii resimlerinde sık olmasa da karşımıza çıkmaktadır. Örneğin, Venüs'ün resmedildiği bir panonun her iki yanında Eros'lar tıpkı Efes örneğinde olduğu gibi girlandların altında uçar vaziyette resmedilmiştir (Resim 8). Efes örneğindeki çok renkli ve süslü girlandların aksine Pompeii girlandları oldukça sade ve tek renkli resmedilmişlerdir.

\section{Teatral Sahne}

Efes'te olduğu kadar Pompeii'de de hem Hellenistik hem de Roma dönemlerinde tiyatroya çok önem verilmiştir. Bir tarafında dağlar diğer tarafında deniz bulunan her iki yerde, açık hava tiyatrosu ve kapalı odeon bulunmaktadır. $\bigcirc$ dönemde aktör ve mim sanatçıları hem sayıca fazladır hem de popülerdir. Bu sanatçılar o kadar popülerdir ki, kentin duvarları onların isimleriyle doludur. Tiyatro konularının da duvar resimlerinde betimlendiḡini görebilmekteyiz. Sayıca en çok olan betimlemeler, evlerin duvar süslemelerinde sıkça rastlanan komik veya trajik maske serileridir. Birçok tabloya ait betimlemeler de teatral konular ilham alınarak yapılmıştır. Örneḡin Orestes, Elektra, Iphigenia, Herakles gibi kahramanların hikayeleri bu resimlerde anlatılmaya çalışılmıştır.

Hellenistik ve Roma dönemlerinde teatral mimikler duyguların aktarılması olarak önem kazanmış ve beḡenilen bir unsur olmuştur. Bununla birlikte, Roma tiyatrosu da Hellen tiyatrosunda olduğu gibi orta sınıfa hitap edebilmiştir. Orta sınıfı etkileyen tiyatro kültürü, Hellen geleneḡinin bir sonucudur. Mozaik ve resimler tiyatronun güçlü etkisini konu edinmişlerdir. Örneğin Homeros Evi'nde bulunan küçük bir mozaik, satirik bir dramın hazırlıklarını resmetmektedir (Maiuri, 1953: 91).

Efes duvar resimleri arasında 1 no'lu konut biriminin tiyatro odasının kuzey duvarında farklı tasvirler görmek mümkündür. Tiyatro odası duvarlarındaki çok renkli panolardan oluşan resimler iyi durumda korunmuşlardır. Ana panolar birbirlerinden korint başlıklı sütunlar ile ayrılmıştır. Kırmızı zeminli panolarda iki ince çerçeve içinde konusu ünlü tragedya ve komedi yazarlarının oyunlarından alınmış tiyatro sahneleri işlenmiştir. Bunlar arasında
Euripides'in 'Orestes' adlı trajedisinden alınmış bir sahnesi canlandırılmıştır (Resim 9). Sahnede bir kline üzerinde yarım yatar durumdaki Orestes, yanında ayakta duran kız kardeşi Elektra ile konuşur durumda gösterilmiştir. (Erdemgil vd., 2001: 21). Diḡer sahnede ise komedi yazarı Menandros'un 'Sikyonioi' adlı komedi oyunu tasvir edilmiştir. Her iki sahne de kırmızı zemin üzerine ve çerçeve içine yerleştirilmiştir. Figürlerin yüzlerinde Roma dönemi tiyatro geleneğine uygun olarak yapılmış mask vardır (Zimmermann ve Ladstatter, 2011: 115, fig.204).

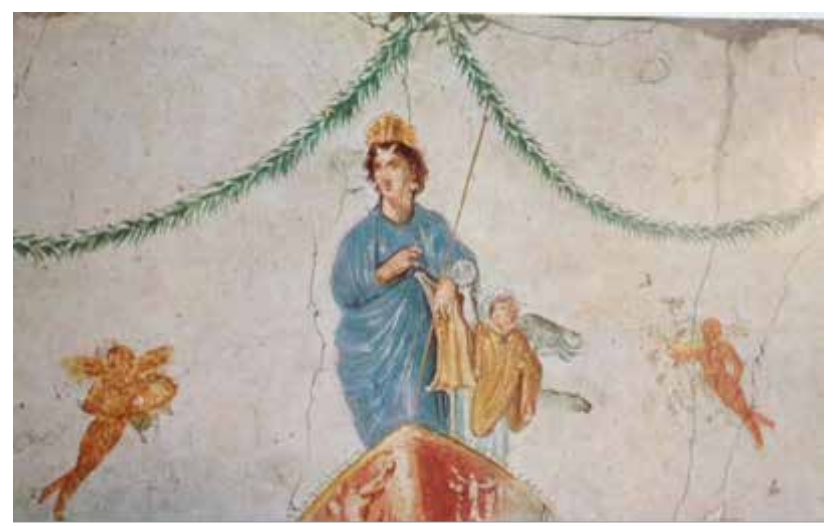

Resim 8. Pompeii, Eros ve girlandlar (Maiuri,1953: 147).

Pompeii'de teatral sahneler arasında komedi, dram, aktörlerin oyuna hazırlanma sürecini gösteren sahneler ve kahramanlar sıklıkla tasvir edilmiştir. Bunlar arasında bir komedi sahnesinin temsilinde yer alan oyuncuların sergilediği mimikler ressam tarafından başarıyla tasvir edilmiştir (Maiuri, 1953: 95) (Resim 10). Antikçağ ressamları arasında insan duygularını tasvir edebilen ilk sanatçılardan biri de Aristeides'tir (Charbonneaux vd., 1973: 125). Buradaki sahnede yer alan üç figürde de şaşkınlık duygusunu ressam gerçekçi bir ifadeyle resmetmiştir.

Yukarıda belirttiğimiz sahneler haricinde, özellikle M. S. 3. yüzyılda Efes'te en çok rastlanan tasvirler arasında hayvanlar, bunlar arasında da balıklar ve kuşlar öncelikli yer almaktadır. Ayrıca, böcekler, girlandlar, sepetler, kuşlar ve çiçekler de resmedilmiştir. Gerçek hayvan tasvirlerinin yanı sıra fabl hayvanlarının da resmedilmiş olması Efeslilerin resim sanatındaki hayal güçlerinin çeşitliliğini yansıtmaktadır. Bu dönemde ayrıca mermer kaplama imitasyonu (Resim 11) ve Efes'e özgün olduğunu 
düşündüğümüz beyaz zemin üzerine serpiştirilmiş çiçek resimleri de ön plandadır (Resim 12). Daha önce benzerine rastlamadığımı serpiştirilmiş çiçek örnekleri, olasılıkla duvarların tamamını resimle kaplama isteği sonucunda gelişmiş olmalıdır (Zimmermann ve Ladstatter, 2011: 134, fig.256). Birçok evin duvar süslemelerinde bu çiçeklerin kullanılması, Efeslilerin beğenisini kazandığının göstergesi olarak düşünebiliriz.

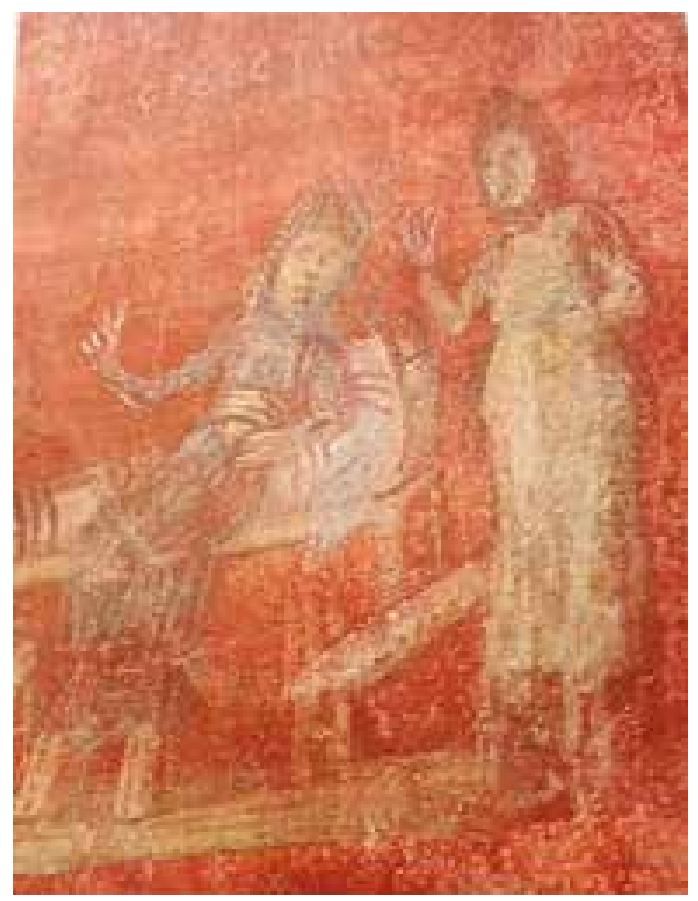

Resim 9. Efes, Teatral sahne (Zimmermann-Ladstatter, 2012: 117, fig.205).

\section{Sonuç}

Doğu ile Batı (Asya ve Avrupa) arasında önemli bir liman kenti olan Efes, çağının en önemli politik ve ticaret merkezi olarak gelişmiş ve Roma İmparatorluk döneminde Asya eyaletinin başkenti olmuştur. Bulunduğu konum nedeniyle Efes sadece doğunun yerel sanatından değil Roma'nın sanatıyla da etkileşim içerisinde olmuştur. Bu etkileri doğal olarak mimarisinde olduğu kadar duvar resimlerinde de görmekteyiz.

Küçük Asya'da Roma Imparatorluk dönemi duvar resimlerini değerlendirmek için Efes duvar resimlerini bilmek gerekir. Evlerin duvarlarını süsleyen bu resimler Pompeii resim stili ile birlikte kendi yerel stilini harmanlayarak yüksek kalitede ve görsellikte resimler yapmışlardır. Efesli ressamların Hellenistik geleneğe bağlı kaldıkları ve bu geleneg̃e olan katkıları tartışımazdır. Bu katkılarından yola çıkarak Efesli sanatçıların da kendilerine özgü bakış açıları olduğu ve değişik anlatım detaylarıyla yeniliklere açık oldukları anlaşılmaktadır. Sanatçıların özellikle duvarlarının tamamının resimlerle kaplama sonucu beyaz zemin üzerine serpiştirilmiş çiçek resimleri Efes duvar resimlerinin en özgün ürünüdür.

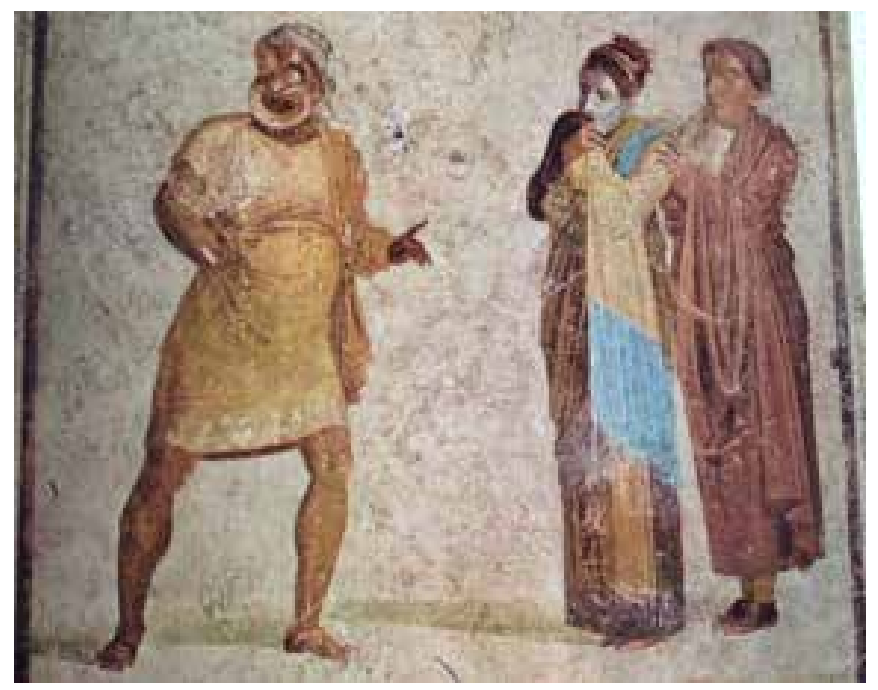

Resim 10. Pompeii, Teatral sahne (Maiuri, 1953: 95).

Efes duvar resimlerinde rastlanan mitolojik konular Pompeii duvar resimleriyle benzerlikler taşımaktadır. Panolarda ince uzun dikey dikdörtgenli ve orta motif olarak tabloların yer aldığı sahneler Pompeii'de de görülür. İtalya ile olan çok yönlü ve yoğun bağı kanıtlayan bu resimler Roma Dönemi'nde evlerin duvarlarını süslemiştir.

Roma Dönemi duvar resimleri Efes'te 1. yüzyıldan başlayarak 3. yüzyıla kadar varlığını sürdürmüştür. Roma Imparatorluğu'nda, özellikle italya'da erken örneklerinin görüldüğü bu duvar resimlerinin Akdeniz'e kıyısı olan bölgelerdeki diğer kentleri de etkilediği şüphesizdir. Bu etkileşimin bölgeler arasındaki ticari bağ sayesinde seyahat eden ressamların ya da taslak resim kitapları vasıtasıyla gerçekleştiği kuşku götürmez bir gerçektir. 


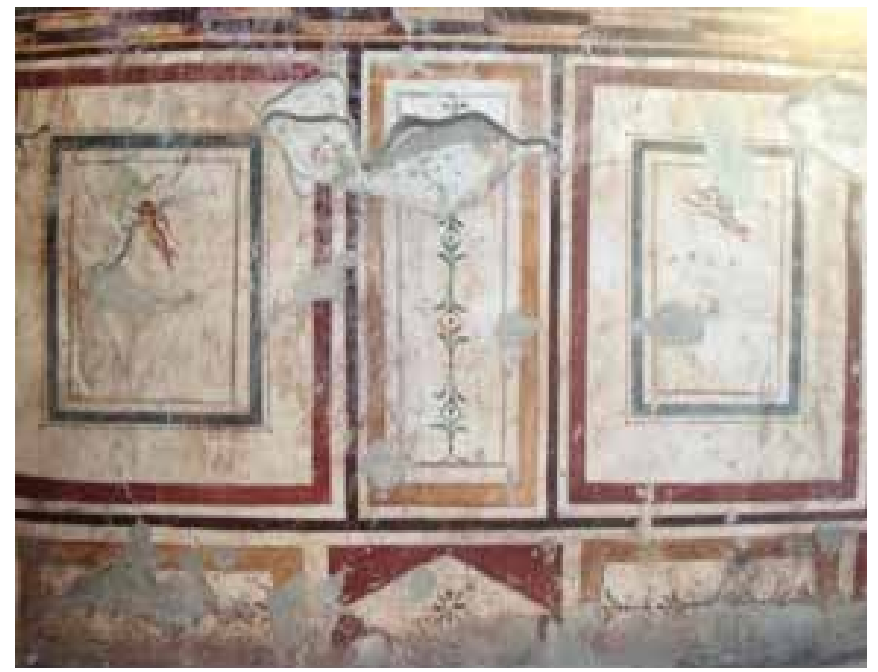

Resim 11. Efes, Mermer levha imitasyonu (Zimmermann-Ladstatter, 2012: 103, fig.171,4).

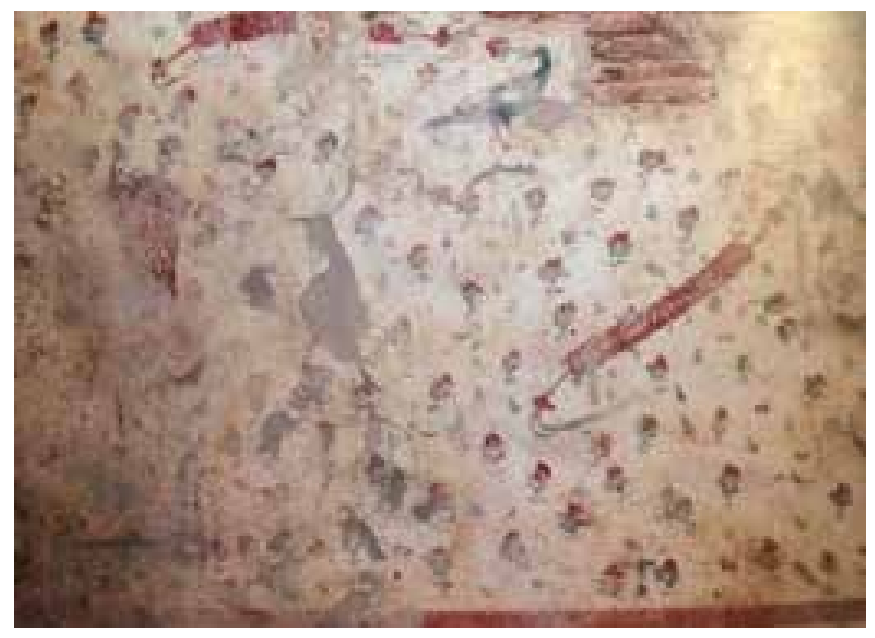

Resim 12. Efes, serpiştirilmiş çiçek resmi (ZimmermannLadstatter, 2012: 96, fig.150,3).

\section{Kaynakça}

Abadie-Reynal, Catherine (2002). "Les maisons à décors mosaïqués de Zeugma" Comptes rendus des séances de l'Académie des Inscriptions et Belles-Lettres, 146- N. 2, 2002. s 743-771.

Apollod. Bibl. (2006). (= Apollodorus, Bibliotheke) Kullanılan metin ve çeviri: The Library, with an English translation by J. G. Frazer, vol I-II, Cambridge, Mass.-London (The Loeb Classical Library).

Arias, Paolo Enrico (1962). A History of Grek Vase Painting, London:Thames and Hudson.

Charbonneaux, J., Martin, R.,Villard, F. (1973). Hellenistic Art (330-50 B.C.), çev. Peter Green. London: Thames \& Hudson.

Cömert, Bedrettin (1999). Mitoloji ve ikonografi. Ankara: Ayraç Yayınevi.

Delbarre, Sophie - Fuchs, Michel -Paratte, Claude-Alain (2007) "Achilles on Skyros: Crossing over Architecture, Mosaic and Wall Painting" 2007,3542. The Proceedings of IV. International Mosaic Corpus of Turkiye. The Mosaic Bridge From Past to Present $=$ IV. Uluslararasi Turkiye Mozaik Korpusu Sempozyum Bildirileri. Gecmisten Gunumuze Mozaik Koprusu, Gaziantep, Uludağ University Press.

Dunbabin, K. M. D. (1999). Mosaics of Greek and Roman World. Cambridge: Cambridge University Press.

Dorigo, Wladimiro (1966). Late Roman Painting. New York: Praeger Publishers.

Eraslan, Şehnaz (2011). Roma Imparatorluk Dönemi Mozaik Sanatında Okeanos ve Tethys Betimlemelerinin Tipolojik ve ikonografik Açıdan Değerlendirilmesi, Yayınlanmamış Doktora Tezi, Konya: Selçuk Üniversitesi - Sosyal Bilimler Enstitüsü.

Erdemgil, S. - vd. (2001). Efes Yamaç Evleri. İstanbul: Hitit Color.

Erhat, Azra (2004). Mitoloji Sözlügü. İstanbul: Remzi Kitabevi.

Grimall, Pierre (1997). Mitoloji Sözlügü, Yunan ve Roma. İstanbul: Sosyal Yayınlar.

Hachlili, Rachel (2009). Ancient Mosaic Pavements: Themes, Issues, and Trends: Selected Studies, Leiden/Boston: Brill.

Homer.Il (1988). (= Homeros, Ilyada) Kullanılan metin ve çeviri ilyada. Çev. Azra Erhat-A.Kadir. Can Yayınları.

Hesiod.Theog. (1966). (= Hesiodos,Theogonia), Kullanılan metin ve çeviriler: Theogony. With an English translation by $M . L$. West. Oxford.

Hesiodos, Theogonia, Eseri ve Kaynakları (1991). çev:: S. Eyüboğlu - A. Erhat. Ankara. 
Hyg.Fab (1933). (= Hyginus. Fabulae.) Kullanılan metin: Ed. H. J. Rose,

Hygini Fabulae.

Ladstatter, Sabine (2012). Ephesos Yamaç Ev 2. çev. Selma Gün. İstanbul: Ege Yayınları.

Ling, Roger (1998). Ancient Mosaics. London: British Museum Press.

Maiuri, Amedeo (1953). La Peinture Romain. Geneva: Skira.Ovid.Met.

(= Ovidius, Metamorphosis ) Kullanılan metin ve çeviri: Dönüşümler, Çev. İsmet. Z.Eyüboğlu, Payel Yayınevi,1997

Önal, Mehmet (2002). Mosaics of Zeugma. İstanbul: A Turizm Yayınları.

Pliny. Natural History, Volume IX, Books 33-35, (Translated by H.Rackham), Loeb Classical Library 1950.

Ragghianti, Carlo Ludovico (1964). The Painters of Pompeii. Milan: Edizioni del Milione.

Robertson, Martin (1992). The Art of Vase-Painting in Classical Athens. Cambridge: Cambridge University Press. Stat.ach (=P. Papinius Statius, Achilleis) Kullanılan metin ve çeviri: Statius. Achilleid. Translated by J.H.Mozley. (The Loeb Classical Library)

Zimmermann, Norbert - Ladstätter, Sabine (2011). Wall Painting in Ephesos from the Hellenistic to the Byzantine Period, Istanbul: Ege Yayınları.

\section{Görsel Kaynaklar}

Resim 1. Akhilleus'un Skyros'ta bulunma sahnesi

(Zimmermann-Ladstatter, 2011: 84, fig.123,3).

Resim 2. Pompeii, Akhilleus'un Skyros'ta bulunma sahnesi (Maiuri, 1953: 73).

Resim 3. Pompeii, Akhilleus'un Skyros'ta bulunma sahnesi (Charbonneaux vd., 1973: 126, fig.124).

Resim 4. Zeugma, Akhilleus'un Skyros'ta bulunma sahnesi (Önal, 2002: 22).

Resim 5. Efes, Sokrates

(Zimmermann-Ladstatter, 2011: 84, fig.127,1).

Resim 6. Pompeii, Filozof

(Maiuri, 1953: 64).

Resim 7. Efes, Eros ve girlandlar

(Ladstatter, 2012: 143, Res.126).

Resim 8. Pompeii, Eros ve girlandlar

(Maiuri,1953:147).

Resim 9. Efes, Teatral sahne

(Zimmermann-Ladstatter, 2012: 117, fig.205).

Resim 10. Pompeii, Teatral sahne

(Maiuri, 1953: 95).
Resim 11. Efes, Mermer levha imitasyonu

(Zimmermann-Ladstatter, 2012: 103, fig.171,4).

Resim 12. Efes, serpiştirilmiş çiçek resmi

(Zimmermann-Ladstatter, 2012: 96, fig.150,3). 